\title{
GESTÃO DO CUIDADO NA ESTRATÉGIA SAÚDE DA FAMÍLIA: REVISÃO NARRATIVA
}

CARE MANAGEMENT IN THEFAMILY HEALTH STRATEGY: NARRATIVE REVIEW

\section{Marinês Tambara Leite ${ }^{a^{*}}$, Janaine Nardino ${ }^{b^{* *}}$, Leila Mariza Hildebrandt ${ }^{c}$, Adriane Marinês dos Santos ${ }^{\mathrm{d}^{*}}$, Ricardo Vianna Martinss ${ }^{\mathrm{e}^{*}}$}

\author{
atambaraleite@yahoo.com.br, bjana.enfer07@yahoo.com.br, cleilahildebrandt@yahoo.com.br, dadriane_santos82@hotmail.com, \\ emartan@smail.ufsm.br \\ *Universidade Federal de Santa Maria - Santa Maria (RS), Brasil \\ **Hospital Tacchini - Bento Gonçalves (RS), Brasil
}

\section{RESUMO}

Introdução: A gestão envolve as práticas dos serviços de saúde e requer reflexôes sobre novas abordagens na produçáo do cuidado, incluindo aquele realizado pela Estratégia Saúde da Família (ESF). Objetivo: Analisar as publicaçóes brasileiras relativas à gestáo do cuidado na ESF, no período de 2006 a 2013. Metodologia: Trata-se de uma revisão narrativa, a busca dos artigos ocorreu nos bancos de dados na Biblioteca Virtual de Saúde (BVS-BIREME), refinando pelas fontes de dados da Literatura LatinoAmericana e do Caribe em Ciências da Saúde (LILACS) e Literatura Internacional em Ciências da Saúde (MEDLINE). Resultados: De 73 artigos encontrados, após a leitura dos resumos, enquadraram-se nos critérios de inclusão 18, e foram analisados segundo os preceitos da análise de conteúdo. As publicaçôes demonstram a importância da gestáo na ESF e apontam que os profissionais devem esforçar-se para atender as necessidades dos usuários e da comunidade, prestando serviço de qualidade e que gere satisfação. Conclusão: Os estudos mostraram que há fragilidades no cuidado ofertado pela ESF e, assim, faz-se necessário desenvolver meios de aprimorar as açôes e intervençóes implementadas por ela. É atribuição dos gestores promover conhecimento e socialização de experiências, para o alcance de melhorias dos serviços de saúde e qualificação da gestấo.

Palavras-chave: Gestão em saúde; estratégia saúde da família; saúde pública; revisão.

\section{ABSTRACT}

Introduction: Health care management comprehends health service practices and demands reflections on new approaches to health care delivery, being included the one carried out by the Family Health Strategy (ESF). Objective: Analyze Brazilian publications in the period 2006-2013, related to health care management in ESF. Methodology: This is a narrative review whose bibliographic research was carried out in Health Virtual Library database (BVS-BIREME) and refined with LILACS database (Latin American and Caribbean Health Sciences Literature) and MEDLINE database (International Literature in Health Sciences). Results: From 73 articles found, after reading the abstracts 18 complied with inclusion criteria and were analyzed according the precepts of content analysis. The publications demonstrated the importance of management in ESF and indicated that professionals should make an effort to attend users' and community's needs, rendering quality services that generate satisfaction. Conclusion: The studies showed that there are fragilities in care provided by ESF and, thus, it is necessary to develop means to improve actions and interventions. Administrators are responsible for promoting knowledge and socialization, in order to achieve improvements in health care service and management qualification.

Keywords: Health care management; family health strategy; public health; review. 


\section{Introdução}

A atenção à saúde tem passado por transformaçóes e reorganizaçóes com significativo avanço. As mudanças de maior impacto tiveram início com a reforma sanitária brasileira e a construção do Sistema Único de Saúde (SUS). Assim, a Constituição Federal do Brasil de 1988 transformou-se no marco teórico e legal que concretizou o entendimento social de promoçáo da saúde, maior conquista do movimento sanitário brasileiro, com garantias de cidadania social ${ }^{1}$.

Nesse contexto, o SUS ampliou o acesso à saúde na atenção básica por meio do Programa de Saúde da Família (PSF) criado em 1994. A partir da necessidade de revisar e adequar às normas nacionais e considerando os princípios e diretrizes, propostos pelo pacto pela vida em defesa do SUS e de gestão, houve a reorganização da atenção básica no Brasil. Esse novo modelo de atenção é composto por equipes multiprofissionais com visão da integralidade, na perspectiva de desenvolver açôes de promoção, proteção e reabilitação da saúde. A Estratégia Saúde da Família (ESF) surgiu com o propósito de ampliar o acesso da população aos serviços básicos de saúde, reorientar o modelo assistencial e focar a família como centro de atenção, com ações no âmbito individual e coletivo ${ }^{2}$.

Desse modo, as práticas de saúde continuamente precisam de investimentos materiais e de recursos humanos para manter a prestaçấo da assistência aos usuários. Isso é um constante desafio para a gestão do cuidado às pessoas diante da efetivação das políticas públicas, no intuito de atender as múltiplas necessidades da população ${ }^{3}$.

Especificamente, em relação à gestão do cuidado, este é considerado o momento de encontro entre profissional/equipe e o usuário, constituindo-se em espaço de diálogo, entre os que possuem necessidades de saúde e os que se dispóem a cuidar. Esse contexto sofre influência de diversos fatores externos como: organizaçōes, crenças, formaçóes. Sendo assim, a ESF proporciona uma mudança no processo de trabalho em saúde, que engloba o profissional, usuário, família e, também, a comunidade, valorizando vínculo e acolhimento ${ }^{4}$.

Cuidado é promover ou disponibilizar tecnologias de saúde conforme a necessidade de cada indivíduo, com o objetivo de proporcionar saúde, bem-estar, segurança e autonomia. Para isso, a gestáo do cuidado em saúde apresenta diferentes dimensóes interdependentes e está atrelada à ação de múltiplos atores ${ }^{5}$.

Três componentes determinam a gestão do cuidado na dimensão profissional. O primeiro é a postura ética, tem a ver como o trabalhador percebe o indivíduo que precisa de cuidados; o segundo diz respeito à competência com que o profissional utiliza e domina seu saber técnico-científico no sentido de solucionar os problemas apresentados pelo paciente; e o terceiro está relacionado à capacidade de formação de vínculo entre ambos 5 .

Diante da configuraçáo do modelo atual de atenção à saúde, observa-se que a gestáo encontra-se em um período de mudanças, de conscientização e, especialmente, de um processo de educação em saúde para a população e para os profissionais que compóem o cenário dos serviços. Entende-se que a gestão do cuidado é uma questão de caráter individual e coletivo e, ao mesmo tempo, deve ser continuamente repensada, analisada e, caso necessário, modificada. Para tanto, há necessidade de se produzir conhecimentos e socializar, especialmente sobre os aspectos da gestão do cuidado na ESF.

Dessa forma, este estudo tem como questão de investigação: $\mathrm{O}$ que tem sido publicado no Brasil sobre a gestáo do cuidado na Estratégia Saúde da Família? Centrado no problema de pesquisa o objetivo deste trabalho é analisar as publicaçóes brasileiras relativas à gestáo do cuidado na ESF, no período de 2006 a 2013.

\section{Metodologia}

Este estudo se caracteriza como uma revisão de literatura, a qual se constitui na busca de informaçôes acerca de determinado tema, com a finalidade de sistematizar a produção do conhecimento sobre um problema de pesquisa. Ao proporcionar os resultados das investigaçôes, essa metodologia pode auxiliar profissionais, pesquisadores e estudantes em suas decisóes, após conhecerem o que tem sido estudado sobre o assunto ${ }^{6}$.

A busca bibliográfica foi desenvolvida na Biblioteca Virtual de Saúde (BVS-BIREME), refinando pelas fontes de dados Literatura Latino-Americana e do Caribe em Ciências da Saúde (LILACS) e Literatura Internacional em Ciências da Saúde (MEDLINE). Essa busca procedeu-se em janeiro de 2014, a partir das palavras "gestão" and "estratégia de saúde da família" and "cuidado". A delimitação temporal foi o período de 2006 a 2013, em que o ponto inicial foi determinado pela reorganização do sistema de atenção básica com a implantação da Estratégia Saúde da Família, em 2006.

Os critérios de inclusão foram: artigos, disponíveis na íntegra em meio eletrônico, redigidos em língua portuguesa. Os critérios de exclusão foram: teses, capítulos de teses, livros, capítulos de livros, anais de congressos ou conferências, artigos de revisão, relatórios técnicos e científicos e documentos ministeriais.

A partir da leitura prévia dos títulos e resumos das 73 produçóes encontradas, foram selecionados 18 
artigos que se enquadraram nos critérios de inclusão. Para o acesso ao texto completo, foram usados os seguintes recursos: link disponível diretamente na base de dados LILACS, portal do periódico em que o artigo foi publicado, portal CAPES e buscador Google.

Para o mapeamento das produçóes científicas, utilizou-se uma ficha constituída das variáveis: publicação, região de produção, objetivo principal e tipo de estudo. Foi desenvolvida a análise de conteúdo ${ }^{7}$, que conta com três etapas: pré-análise, exploração do material e interpretação dos resultados. Realizou-se leitura flutuante, a qual possibilitou ter uma visão abrangente do conteúdo. Na sequência houve a leitura integral do artigo, que permitiu identificar resultados e extrair trechos significativos. Em seguida ocorreu a releitura dos textos, quando foi possível construir uma categoria temática, observando as convergências, divergências e semelhanças do conteúdo existentes.

\section{Resultados e discussão}

Dos 18 artigos analisados na íntegra, verificou-se que a regiáo brasileira de procedência dessas produçóes com maior destaque foi a Sudeste (9), seguida pela Nordeste (6), Centro-oeste (2) e Sul (1). Em relação ao ano, identificou-se que há maior número de títulos publicados no período compreendido entre 2009 e 2012, em que houve de 3 a 6 trabalhos por ano. $\mathrm{O}$ ano 2007 teve uma publicação e observou-se que os anos 2006, 2008 e 2013 não tiveram publicaçóes abordando a temática em estudo. Quanto ao tipo de estudo observou-se que há predomínio de pesquisas de natureza qualitativa (10), seguida relato de experiência e estudo de caso, com três publicaçốes em cada categoria. Teve ainda uma investigação de caráter quantitativo e uma pesquisa quali-quantitativa. Esses dados podem ser observados no quadro a seguir:

Quadro 1: Distribuição dos artigos analisados, segundo referência, tipo de estudo e objetivo principal.

\begin{tabular}{|c|c|c|c|}
\hline COD & Artigo & Tipo de estudo & Objetivo principal \\
\hline $\mathrm{A} 1$ & $\begin{array}{l}\text { Maxta BSB, Almeida AB, Silveira LB, Soleman C, } \\
\text { Ogata MN. Educaçáo popular em saúde a partir de um } \\
\text { jogo: gestấo e cuidado em uma unidade de Saúde da } \\
\text { Família. Trab. educ. saúde [online]. 2010; 8(1):155-66. }\end{array}$ & $\begin{array}{l}\text { Relato de } \\
\text { experiência }\end{array}$ & Não consta \\
\hline A2 & $\begin{array}{c}\text { Barrêto AJR, Romera AA, Oliveira AA, Sá LD, } \\
\text { Almeida AS, Nogueira JA. Trabalho do apoiador } \\
\text { matricial na Estratégia Saúde da Família. Rev. RENE. } \\
\text { 2012;13(1):166-77. }\end{array}$ & $\begin{array}{c}\text { Pesquisa } \\
\text { qualitativa }\end{array}$ & $\begin{array}{l}\text { Conhecer o processo de trabalho dos apoiadores } \\
\text { matriciais que atuam na Estratégia Saúde da } \\
\text { Família }\end{array}$ \\
\hline A3 & $\begin{array}{l}\text { Costa-e-Silva V, Rivera FJU, Hortale VA. Projeto } \\
\text { Integrar: avaliação da implantação de serviços integrados } \\
\text { de saúde no Município de Vitória, Espírito Santo, Brasil. } \\
\text { Cad. saúde pública. 2007; 23(6):1405-414. }\end{array}$ & Estudo de caso & $\begin{array}{l}\text { Descrever uma experiência de integração entre } \\
\text { serviços de saúde -Projeto Integrar }\end{array}$ \\
\hline A4 & $\begin{array}{l}\text { Dimenstein M, Sales AL, Galvão E, Severo AK. } \\
\text { Estratégia da atenção psicossocial e participação da } \\
\text { família no cuidado em saúde mental. Physis. 2010; } \\
\qquad 20(4): 1209-26 .\end{array}$ & $\begin{array}{c}\text { Pesquisa } \\
\text { qualitativa }\end{array}$ & $\begin{array}{l}\text { Discutir como familiares de portadores de trans- } \\
\text { tornos mentais têm experienciado as mudanças } \\
\text { nas políticas da área, o que pensam sobre as novas } \\
\text { demandas de participaçáo e como têm impactado } \\
\text { na sua relaçáo cotidiana com os serviços de saúde } \\
\text { mental e nas práticas de cuidado com seus familiares }\end{array}$ \\
\hline A5 & $\begin{array}{l}\text { Camuri D, Dimenstein M. Processos de trabalho em } \\
\text { saúde: práticas de cuidado em saúde mental na estratégia } \\
\text { saúde da família. Saúde Soc. } 2010 ; 19(4): 803-13 \text {. }\end{array}$ & $\begin{array}{l}\text { Pesquisa de } \\
\text { campo }\end{array}$ & $\begin{array}{l}\text { Refletir sobre processos de trabalho em saúde na } \\
\text { rede básica do Sistema Único de Saúde (SUS) em } \\
\text { relaçáo ao cuidado em saúde mental }\end{array}$ \\
\hline A6 & $\begin{array}{l}\text { Arce VAR, Sousa MF, Lima MG. A práxis da Saúde } \\
\text { Mental no âmbito da Estratégia Saúde da Família: con- } \\
\text { tribuiçóes para a construção de um cuidado integra- } \\
\text { do. Physis. } 2011 ; 21(2): 541-60 .\end{array}$ & $\begin{array}{l}\text { Pesquisa quali- } \\
\text {-quantitativa }\end{array}$ & $\begin{array}{l}\text { Analisar as práticas de Saúde Mental na atuação } \\
\text { das equipes da ESF de Brazlândia, no Distrito } \\
\text { Federal, quanto a seus potenciais e limites para } \\
\text { o cuidado integral aos sujeitos em situaçóes de } \\
\text { sofrimento mental na atençáo primária }\end{array}$ \\
\hline A7 & $\begin{array}{l}\text { Bellenzani R, Mendes RF. Entre o empenho, o acolhi- } \\
\text { mento e a impotência: dilemas de agentes comunitárias } \\
\text { de saúde na produçáo do cuidado e da humanizaçáo. } \\
\text { Cad. Ter. Ocup. UFSCar. 2012;20(2):239-53. }\end{array}$ & $\begin{array}{c}\text { Pesquisa } \\
\text { qualitativa }\end{array}$ & $\begin{array}{l}\text { Discutir a respeito da dimensão intersubjetiva do } \\
\text { trabalho dos agentes de saúde na interação com } \\
\text { usuários, na medida em que suas concepçóes e } \\
\text { práticas tendem a se aproximar dos princípios e } \\
\text { dispositivos da PNH, especialmente das noçóes } \\
\text { de acolhimento, humanização e atenção integral }\end{array}$ \\
\hline
\end{tabular}


Quadro 1: Continuação.

\begin{tabular}{|c|c|c|c|}
\hline COD & Artigo & Tipo de estudo & Objetivo principal \\
\hline A8 & $\begin{array}{l}\text { Teixeira MG, Rates SMM, Pimenta Jr FG, Ferreira JM, } \\
\text { Carvalho MJM. Construindo a Política Pública de Saúde } \\
\text { em Belo Horizonte: O Sistema Único de Saúde no muni- } \\
\text { cípio. Divulg. saúde debate. 2012; (48):97-103. }\end{array}$ & $\begin{array}{l}\text { Relato de } \\
\text { experiência }\end{array}$ & $\begin{array}{l}\text { Apresentar as especificidades da construção do } \\
\text { SUS no espaço urbano (território) do município } \\
\text { de BH, sua organizaçáo e a gestáo dos serviços de } \\
\text { saúde na cidade, com destaque para os desafios, o } \\
\text { planejamento e as proposiçóes para os tempos atuais }\end{array}$ \\
\hline A9 & $\begin{array}{l}\text { Ferreira VSC, Andrade CS, Franco TB, Merhy EE. } \\
\text { Processo de trabalho do agente comunitário de saúde e } \\
\text { a reestruturação produtiva. Cad. saúde pública. 2009; } \\
\text { 25(4):898-906. }\end{array}$ & Estudo de caso & $\begin{array}{l}\text { Verificar as singularidades da realidade, do vivido, } \\
\text { nos quais estão em produçáo trabalhadores e usuá- } \\
\text { rios com seus sentidos, significados, sonhos, desejos, } \\
\text { crenças, valores e atitudes em constante processo de } \\
\text { singularizaçáo e também de serializaçóes }\end{array}$ \\
\hline
\end{tabular}

Rosa TEC, Bersusa AAS, Mondini L, Saldiva SRDM, Nascimento PR, Venancio SI. Integralidade da atenção às A10 doenças cardiovasculares e diabetes mellitus: o papel da regionalização do Sistema Único de Saúde no estado de São Paulo. Rev. bras. Epidemiol. 2009;12(2):158-71.
Analisar indicadores de estrutura, processo e de Pesquisa resultados da atenção à saúde do adulto, especificaquantitativa mente de diabetes mellitus e hipertensão arterial, à luz da regionalização do SUS no estado de São Paulo

Analisar como os profissionais médicos da Atenção Básica em Saúde na Estratégia Saúde da Família realizam o cuidado integral individual, tendo como foco a dimensão psicológica no processo saúde doença das pessoas

Pesquisa qualitativa
Araújo JL, Paz EPA, Moreira TMM. Hermenêutica e o cuidado de saúde na hipertensão arterial realizado por enfermeiros na estratégia saúde da família. Esc Anna Nery. 2010;14(3):560-66.

Jonas LT, Rodrigues HC, Resck ZMR. A função gerenA13 cial do enfermeiro na estratégia saúde da família: limites e possibilidades. Rev. APS. 2011;14(1):28-38.

Backes DS, Backes MS, Erdmann AL, Büscher A. O papel profissional do enfermeiro no Sistema Único de Saúde: da saúde comunitária à estratégia de saúde da família. Ciência \& Saúde Coletiva. 2012;17(1):223-30.

Barros SCM, Dimenstein M. O apoio institucional como A15 dispositivo de reordenamento dos processos de trabalho na atenção básica. Estud. pesqui. psicol. 2010;10(1):sp.
Pesquisa qualitativa
Compreender os sentidos atribuídos ao cuidado de saúde na hipertensão por enfermeiros na Saúde da Família em Pau dos Ferros/RN
Vasconcelos EM, Silveira MFA, Eulalio MC, Medeiros PFV. A normatização do cuidar da criança menor de um A16 ano: estudo dos significados atribuídos pelos profissionais do Programa Saúde da Família (PSF). Ciênc. saúde coletiva. 2009;14(4):1225-34.

\section{Pesquisa Compreender e analisar os limites e as possibili- qualitativa dades do processo de trabalho gerencial do enfer- meiro na equipe do Programa Saúde da Família}

Possibilitar um olhar retrospectivo do papel profisPesquisa sional do enfermeiro no SUS brasileiro, bem como qualitativa compreender o significado de sua prática social neste campo de discussóes e significaçôes teórico-práticas

Relato de Identificar no discurso das equipes, os limites experiência e desafios desse encontro entre saúde mental e atenção básica

Villari APS, Souto BGA. Organização funcional da rede A17 de saúde de um município de São Paulo na percepção de um usuário. Rev APS. 2012;15(4):404-11.

Estudo de caso

Conhecer e avaliar a experiência do SUS de São Carlos/SP, com sua rede de cuidados à saúde
Azevedo AM, Costa AM. A estreita porta de entrada do Sistema Único de Saúde (SUS): uma avaliaçáo do acesso A18 na Estratégia de Saúde da Família. Interface (Botucatu). 2010;14(35):797-810.
Analisar a percepção dos usuários sobre o acesso à ESF em suas dimensôes geográfica, organizacional, sociocultural e econômica 
Da análise de conteúdo dos artigos, elaborou-se uma categoria temática que versa acerca da Estratégia Saúde da Família como espaço de gestão da atenção à saúde.

\section{A ESF como espaço de gestão da atenção à saúde}

A leitura dos textos possibilitou identificar que o modelo Estratégia de Saúde da Família (ESF) coloca a comunidade e o usuário no centro do processo de formulação e operacionalização das políticas e açôes de saúde, ampliando sua participação na gestão e consolidação do Sistema Único de Saúde (conforme mostrou o estudo A1). Além disso, utiliza a estrutura de Apoio Matricial (AM) para ampliar e dar cobertura às ações de saúde, aproximando os profissionais da ESF com a comunidade, criando o vínculo necessário para obter os relatos, vivências, inquietaçôes, medos, sugestôes, reclamaçôes, desabafos, entre outras necessidades das pessoas. Desse modo, é possível desenvolver uma gestão diferenciada na atenção à saúde e, consequentemente, realizar açôes de cuidado integral para a população.

Nesse sentido, estudo A2 menciona que o AM configura-se como um elo e atua articuladamente - equipe e rede assistencial - operando como uma açáo de reflexão e remodelaçáo das práticas de saúde, por meio da reorganização do processo de trabalho da ESF. Refere, ainda, que os encontros do AM se tornam essenciais para identificar as dificuldades que a equipe de saúde, por vezes, náo consegue perceber. Para tanto, constroem soluçóes a partir de um planejamento de gestão participativa, em que são estabelecidas trocas de saberes entre os profissionais de diferentes serviços que estão envolvidos no cuidado ao usuário. Assim, esses aspectos se tornam importantes para o desenvolvimento de práticas de saúde, cuja maior finalidade é a construção do cuidado integral e humanizado, conforme preconiza o SUS.

Sendo assim, o AM é uma forma de organizar e ampliar a oferta de açóes em saúde e, desse modo, faz o usuário ser cliente, favorecendo a construção de vínculo e responsabilização das equipes. Com isso, é uma ferramenta indispensável para a atençáo e a gestão à saúde, uma vez que possibilita o atendimento integral, aumentando a capacidade de resolver os problemas que a equipe apresenta. O AM serve como um suporte técnico ofertado a uma equipe interdisciplinar de saúde para ampliar seu campo de atuação e qualificar suas ações. Ele também é considerado um recurso que facilita o cuidado em saúde, presta atendimento individualizado, respeitando suas subjetividades e mantendo o contato com a família. Além disso, incentiva o comprometimento com a equipe da ESF com os problemas de saúde dos usuários, sem quebrar o vinculo já estabelecido ${ }^{8}$.
Contudo, ainda há fragilidades na consolidação das diretrizes preconizadas pelo SUS, pois uma pesquisa (A3) que envolveu trabalhadores e gerentes do cuidado integral ao usuário apontou que há necessidade de ampliar o vínculo entre profissionais de saúde e a população, além de qualificar o acolhimento aos usuários que procuram o serviço de ESF. Os autores mencionam que, a partir do estudo, foi possível reorganizar os processos de trabalho, em que gestores da ESF desenvolveram formas alternativas de gestão, com a finalidade de prestar atendimento de qualidade para a população.

Ainda, como meio de gerenciar a atençáo à saúde, o estudo A3 mostra que os Agentes Comunitários de Saúde (ACS) identificam os problemas de saúde dos usuários e que esses profissionais são elementos importantes para a equipe e os serviços da comunidade. Também, o vínculo construído entre usuário/comunidade e equipe auxilia os ACS e contribui na qualificação da atenção prestada à comunidade.

No entanto, publicaçóes (A4, A5, A6) apontam problemas na atenção básica e sua integração com as equipes de saúde, em que há falta de domínio técnico de determinadas áreas como saúde mental, por parte dos profissionais, de limites para as suas atuaçóes; falta de vínculos com esses usuários e suas famílias, sendo que o papel do ACS mediar o processo e; necessidade de formação continuada para a equipe. Isso porque náo basta inserir profissionais na atenção básica, estes devem estar capacitados para detectar os problemas de saúde e ter propostas de intervençóes adequadas, para melhor organização e gestão do trabalho e para a qualidade da atenção aos usuários.

O acolhimento e vínculo são dois conceitos de extrema importância para o desenvolvimento e atendimento do usuário que apresenta problemas de saúde mental. $\mathrm{Na}$ atenção básica, o acolhimento e vínculo se tornam norteadores da assistência, contribuindo para o atendimento humanizado. É essencial que haja a inclusão do doente mental nos serviços da ESF, tendo por base o princípio da igualdade na assistência à saúde .

Ao serem integrantes da comunidade, os ACS tornam-se mediadores e facilitadores da relação entre serviço de saúde e usuário. Além disso, por terem facilidade de estabelecer vínculos e contatos, o ACS torna-se um importante instrumento na atenção em saúde mental. Em relaçáo aos cuidados oferecidos às pessoas com transtorno mental na atenção básica, os ACS são os profissionais que mais têm postura cordial, afetiva e compreensiva, o que facilita a relação?.

O vínculo entre usuários e ACS gera confiança mútua, o que é essencial para o sucesso do trabalho da equipe. Essa confiança se dá pelo elo que os ACS têm com as famílias, pois nas visitas a suas casas, conhecem seus hábitos, costumes, problemas, necessidades que o restante da 
equipe não fica conhecendo. É por meio dos ACS que, comumente, se obtêm informaçôes sobre os usuários e as situaçôes de riscos das famílias.

$\mathrm{Na}$ maioria das vezes o ACS assume a responsabilidade de manter a interação entre a população e a equipe de saúde da família ${ }^{10}$. É o ACS que vive na comunidade do usuário, que convive mais tempo com ela e sabe sobre as realidades do local, dos problemas, satisfaçóes e insatisfaçôes do ambiente ${ }^{11}$.

Estudo A7 descreve a interação dos usuários com os ACS, o qual aponta que faltam conhecimento e capacitação a esses profissionais. Os usuários cobram mais conhecimentos e isso prejudica o bem-estar dos ACS, pois se sentem pressionados, estressados e cansados, ficando desacreditados diante da população. Esses sentimentos devem ser reconhecidos e considerados no planejamento da gestão, para que isso não prejudique o trabalho dos ACS.

Qualidade dos serviços implica assumir compromissos com a integralidade, universalidade e repensar nos modelos de atenção e de gestão. O desafio consiste em intensificar açōes que permitam aprimoramento do sistema, fortalecendo a atençáo integral e resolutiva à população, com efetividade e responsabilidade. Para tanto, no estudo analisado, evidencia-se aposta na educação permanente, com a finalidade de aperfeiçoar e reciclar os conhecimentos, contribuindo na qualificação das práticas assistenciais. Vale destacar que, após a implementação da ESF, o estudo A7 menciona que as equipes de saúde enfrentaram um dilema de gestão, em que havia o desafio de disseminar e coletivizar as diretrizes institucionais do processo de trabalho local.

Assim, percebe-se que a capacitação e melhor formação desses profissionais merecem atenção dos gestores diante das importantes contribuiçôes dos ACS para a atenção básica. A atuação dos ACS em saúde mental muitas vezes se agrava, pois há falta de conhecimento específico nessa área. Também eles se veem impotentes em função do desconhecimento e da pouca resolutividade que podem apresentar. No caso da saúde mental, muitos ACS acompanham usuários e suas famílias com transtornos mentais e sentem dificuldade em atender à demanda, além de temerem por sua integridade física e psicológica. Sendo assim, justifica-se uma melhor capacitaçáo desses membros da equipe de saúde para uma assistência de melhor qualidade ${ }^{12}$.

Outro estudo analisado (A8) teve por objetivo relatar a experiência da construção de um modelo de atenção à saúde. Nele os autores apontam que para garantir a integralidade do cuidado, com eficiência e qualidade, são necessárias ações organizadoras que facilitem o vínculo com a populaçáo e promovam o cuidado de qualidade. Para tanto, é importante ampliar a capacidade das equipes, avançar e agregar o saber dos usuários.
No decorrer da construção do sistema de saúde, há possibilidade de os profissionais, junto com a população, criarem mudanças na proposta da ESF, em que o trabalho em equipe é uma forma eficiente de estruturação, organização e de aproveitamento das habilidades humanas. Com participação coletiva, é possível ter uma visão mais global e coletiva do trabalho, reforçando o compartilhamento de tarefas e, juntos, alcançando os objetivos comuns. Se não houver a interação entre profissionais e usuários, corre-se o risco de ter uma prática fragmentada, desumanizada e centrada no enfoque individual ${ }^{13}$.

Açôes de promoção e prevenção, com atendimento integral, são fortalecidas a partir do vínculo construído entre profissionais e usuários, uma vez que este gera confiança, contribuindo para a saúde individual e coletiva e proporcionando melhor assistência à saúde do usuário $^{13}$. Nessa mesma linha de discussão, o estudo A9 realizado com o objetivo de analisar a produção do cuidado dos ACS, tendo as tecnologias de cuidado e a caracterização da reestruturação produtiva como principais marcadores de processo de trabalho, identifica que a subjetividade entre a equipe e os usuários amplia os espaços de compartilhamento da gestão do cuidado pela equipe.

Outro aspecto, para o modelo de organização da gestão do cuidado e do trabalho que se estrutura por relações hierarquizadas, é que o ACS reproduz um modo de produçáo do cuidado centrado em procedimentos. Isso subestima os outros saberes e manifesta-se como o saber-cuidador, balizado em tecnologias relacionais que mantém a equipe pouco permeável a inovaçôes no processo de trabalho do ACS. A análise mostra que os ACS, por náo terem espaço para a elaboração de planejamento do trabalho, necessitam criar estratégias de gestâo colegiada, para discutirem e resolverem os problemas. As tecnologias ligadas ao processo de trabalho em saúde têm contribuído para a gestáo do cuidado e para os trabalhos dos serviços de saúde, por possibilitarem a identificação de ruídos, potencialidades, limites, presentes na malha progressiva de cuidado à saúde.

Quanto às linhas de cuidado, pesquisa A10 mostra que estas são, frequentemente, instrumentos fundamentais para a organização da atenção em saúde. Desse modo, manifesta-se a necessidade de maior articulação entre os sistemas dos municípios e o fortalecimento das secretarias estaduais de saúde, para regular a organização de redes assistenciais e, com isso, obter resultados positivos para a saúde da população. Nesse cenário, a linha de cuidado é um modelo ideal para a organizaçáo assistencial e para a integralidade. Além disso, as práticas gestoras adequadas para a organização eficiente da atençấo à saúde depende do aprimoramento do conhecimento sobre o SUS entre os gestores, profissionais e a população. 
A linha de cuidado é uma estratégia para a ação, um caminho para a obtenção da atenção integral, que é um dos princípios do SUS. O cuidado significa que não é só o cuidar de si, e sim o cuidado do outro. Este deve estar relacionado a uma prática humanizada e integral, com princípios e estratégias que norteiam a relação entre o paciente e o profissional de saúde. Desse modo, a linha de cuidado é uma forma de organização da atenção integral à saúde, com o propósito de orientar os gestores e profissionais de saúde, com vistas à continuidade do atendimento, fortalecendo, assim, a responsabilidade dos serviços ${ }^{14}$.

$\mathrm{O}$ vínculo terapêutico, entre equipes e usuários, estimula uma progressiva responsabilidade pela coprodução de saúde. Assim, os gestores devem centrar-se nos usuários e serem seguidos por todos os trabalhadores, construindo uma rede de serviços e comprometimentos com a produção do cuidado. Contudo, estudo evidencia, também, dificuldades na reorganização do processo de trabalho em saúde por parte dos médicos, tanto na unidade como na gestão da realizaçáo do cuidado e de como o usuário vê o profissional, dificultando a interação com o usuário (A11).

Um dos motivos da falta de interação dos usuários com os médicos é o excesso de demanda, prejudicando a qualidade do atendimento e interferindo na relação médico-paciente. Também, há muita rotatividade dos médicos devido à insatisfação profissional e salarial, isso dificulta a criação do vínculo adequado com a populaçáo, o que a leva a não realizar acompanhamento regular, limitando-se a atendimentos eventuais ${ }^{15}$.

Outra pesquisa (A12) realizada para conhecer as práticas de cuidado realizadas por enfermeiros mostra situações que desencadeiam prejuízos à saúde da população. Uma das dificuldades encontradas foi ausência do trabalho em equipe na execução das açôes de saúde. Os enfermeiros relatam que se sentem sobrecarregados com as atribuiçôes que têm para com a população e com a organização das ESF. Mencionam, também, que têm dificuldade para dialogar com os demais membros da equipe da unidade. Sendo assim, o trabalho se torna fragmentado e individualizado, o que náo favorece para as mudanças em suas açóes. Os resultados, ainda, mostram que eles se sentem desassistidos pela gestão local para trabalhar junto com os usuários e com sobrecarga de responsabilidades, o que inviabiliza sua dedicação ao cuidado das pessoas.

$\mathrm{Na}$ investigação $\mathrm{A} 12$, os profissionais demonstram que há necessidade de reorganização da gestão para que seu trabalho seja coletivo, sistemático e que cada usuário tenha atendimento de qualidade, desde o momento da chegada à unidade de saúde até o momento do seu retorno. Reforçam a ideia da utilização do planejamento e avaliações das ações do ESF, de fazer uma nova discussão com os gestores e demais membros da equipe de saúde, para gerar mudanças no processo do cuidado.

Uma das publicaçóes analisadas (A13) mostra que uma das funções do enfermeiro é gerenciar e ser responsável por identificar como está organizado o atendimento ao usuário e como este se relaciona com a equipe. Com as funçóes de gerenciar e de prestar assistência, muitas vezes, o enfermeiro fica sobrecarregado e não realiza as açóes de cuidado adequadamente, causando estresse e insatisfação nos usurários. Entretanto, a gestão de ESF é um modelo que favorece para a realização do cuidado de enfermagem, otimizando interrupçôes em saúde de tal forma que contemple os saberes dos profissionais e dos usuários (A14).

Pesquisa A15 mostra que as dificuldades encontradas pela equipe de saúde podem ser sanadas com mudanças na forma de organização do processo de trabalho. Para tanto, a equipe promoveu encontros quinzenais para discutir os processos e a organização do trabalho, com a proposta de desdobramento do procedimento de apoio institucional. As questôes referentes à organização dos serviços eram trazidas a todo o momento, no decorrer dos encontros, e era apontada a insuficiência de recursos humanos como um dos problemas responsável pela sobrecarga de trabalho dos profissionais. A falta de acessibilidade dos usuários aos serviços em função da burocracia administrativa também era um fator de adoecimento da equipe, desenvolvendo sentimentos de angústia e impotência.

$\mathrm{Na}$ realidade, ninguém vive sem estresse. Ele é parte inerente de todo ser humano e tem pontos positivos. No entanto, é necessário aprender a lidar com o estresse e mantê-lo sob controle. A função gerencial faz parte da rotina do enfermeiro assim como a função assistencial, sendo interligadas. Para que ocorra um bom gerenciamento é preciso planejar e ter o envolvimento de todos, inclusive dos usuários. Muitas vezes, o enfermeiro encontra dificuldade em gerenciar, devido à falta de profissionais e, nessa situação, há sobrecarga de trabalho e ocorre prejuízo na assistência à população. Os enfermeiros devem saber lidar com os problemas do dia a dia, não culpando os usuários, ofertando a eles assistência de boa qualidade. Também, os profissionais da equipe da ESF devem ser capazes de respeitar as diferenças culturais, sociais, econômicas utilizando como instrumento de trabalho a escuta, o acolhimento, o estabelecimento de vínculo e a responsabilização ${ }^{16-17}$.

Nessa mesma linha de entendimento, pesquisa A16 buscou identificar o cuidado realizado pelos profissionais com crianças menores de 1 ano em um Programa de Saúde da Família (PSF), no qual o maior desafio dos profissionais foi integrar-se à rede do sistema de saúde. Isso porque pressupóe a organizaçáo de um sistema de referência e contrarreferência, com fluxos e percursos 
definidos, constituído de acordo com a demanda populacional. $\mathrm{O}$ referido estudo mostra que os profissionais possuem dificuldades devido à descontinuidade da assistência, o que lhes causa impotência e desilusáo. Outra dificuldade é a manutenção de equipamentos tecnológicos que possibilitam bom atendimento. Sendo assim, o estudo pontua que grande parte dos problemas evidenciados pode ser resolvida com açóes simples e de baixo custo, só falta uma política de gestão comprometida com a efetiva mudança. Dentre as dificuldades apresentadas, está a descontinuidade na implantação de açôes ${ }^{18}$. Essa situação interfere na autonomia e interfere no processo de trabalho dos profissionais.

As organizaçóes se constituem de acordo com a concepção de saúde e desconhecem as histórias de vida das pessoas. As especialidades levam a fragmentação do cuidado, já que não cuida do paciente como um todo e, com a sobrecarga de trabalho, a consequência é a descontinuidade da atençãá ${ }^{18}$.

Outro aspecto apontado pelos profissionais e usuários dos serviços de saúde está relacionado aos elementos que produzem (in)satisfação a um deles ou a ambos. Artigo A1 relata a experiência da criaçáo de encontros por meio dos quais seria possível identificar as fragilidades da ESF e, assim, melhorar o atendimento e a satisfaçáo dos usuários. Foi realizada uma reunião na qual a temática debatida era saúde e cuidado. A partir do segundo encontro, os usuários, um pouco mais à vontade, relataram aos profissionais a importância da rapidez no atendimento, da escuta do paciente e a sensação de descrença no serviço. Também, emergiram manifestaçôes sobre a falta de esclarecimentos pelo profissional e o desrespeito para com o usuário. Além disso, outros assuntos foram levantados tais como: a relação público-privado do sistema de saúde, a saúde como mercadoria, o direito do usuário e o dever do profissional, a fragmentaçáo do cuidado e conflitos profissionais, causando insatisfação no usuário.

Com o passar dos encontros, os usuários mostraram-se mais seguros em falar suas inquietaçōes, uma vez que aumentou os relatos queixosos quanto à assistência prestada, à espera no atendimento, às consultas longinquamente agendadas. Com isso, os usuários saíam dos encontros muito satisfeitos, afirmando que pretendiam voltar ao espaço e chamar mais pessoas para participar, pois ali era o momento deles exporem o que estavam sentindo quanto ao serviço prestado e o que poderia mudar e contestar à gestão municipal. Da troca de vivências, apareceram as mudanças de postura entre a equipe e o usuário, o que fortalece a gestão compartilhada dos serviços ou das ações sociais de seus atores e a participação social A1.

A insatisfação do usuário reflete também na insatisfação do profissional, pois implica resultados da assistência prestada. Indivíduos mais satisfeitos apresentam melhor qualidade de vida e menos índices de adoecimento físico e mental. Para o usuário, não basta agendar a consulta, realizar um determinado procedimento técnico, perguntar sobre a queixa e orientar, é preciso mais qualidade, disponibilidade e interesse, demonstrar compreensão e ajudá-lo a descobrir alternativas para o problema do usuário ${ }^{19}$.

Outro estudo (A17) buscou comparar o atendimento prestado por serviço privado com o do serviço público, com base na vivência de uma pessoa. Em uma determinada situação, a usuária tinha uma expectativa positiva, pois se tratava de um serviço privado, especialmente em relação à agilidade no atendimento, mediada, também, pela crença de que, como cliente antiga do médico, essa etapa seria agilizada. No entanto, seu sentimento foi de grande frustração, pois a organização e o longo tempo de espera lhe causaram grande angústia, insatisfação e falta de acolhimento. Optou, então, por procurar o serviço público que, mesmo com muitas tentativas, houve falta de agilidade. A alternativa encontrada foi esperar o tempo passar. Outra surpresa foi que, em nenhum momento, foi identificada, por algum serviço de saúde, uma possibilidade de alívio de suas angústias e acolhimento.

A produção do cuidado sem acolhimento gera insatisfação dos usuários e a não resolução de suas necessidades. A falta de acolhimento vinculado à dificuldade de acesso ao serviço de saúde está relacionada com baixa resolutividade no atendimento às necessidades de saúde da população, contrariando os princípios do SUS e as expectativas dos usuários ${ }^{20}$.

Nessa mesma direção, pesquisa A18 teve como objetivo avaliar o acesso do usuário à ESF e sua satisfação com o serviço recebido. Os resultados revelam que o serviço não satisfaz a necessidade dos usuários. Um dos motivos pela insatisfação é de que os usuários têm dificuldades para agendar consulta médica, a qual parece ser a mais sentida pela população; o mau funcionamento do sistema de referência e contrarreferência, comprometendo o acesso a especialistas; o excessivo número de pessoas adscritas na área das equipes; a demora na sala de espera para receber o atendimento; o retardo no recebimento dos resultados de exames; o despreparo dos profissionais e usuários quanto à organização e execução de açóes conjuntas; e a espera pelo atendimento nas situaçóes de urgência. Essa fragilidade na atenção a saúde é atribuída ao despreparo dos profissionais e usuários quanto à organizaçáo e execução de açóes conjuntas; a baixa capacidade de visualizar a perspectiva coletiva da saúde, situada no campo da cidadania e as despesas com medicamentos e outros insumos.

O estudo A18 sinaliza o ponto de vista da gestora da unidade de saúde em relação às dificuldades, apontando o número excessivo de encaminhamentos. 
A comunicaçáo e a troca de informaçóes entre profissionais são importantes para a função de coordenação atribuída à ESF e para a garantia de continuidade do cuidado.

A limitação de acesso a consultas especializadas, exames complementares, demora no atendimento se contrapóem ao direito à cidadania e aos princípios do SUS, em que os usuários ficam expostos e, muitas vezes, a condiçãa de saúde se agrava. Além disso, essa situação gera desconforto para os profissionais da ESF, a quem cabe dar respaldo nessas condiçóes ${ }^{21}$.

A insatisfação é definida como uma expressão negativa e ocorre no momento que o usuário se sente descontente ou decepcionado com o desempenho de um serviço, no qual não atingiu suas expectativas ${ }^{22}$. Vale destacar que a insatisfação dos usuários em relação à atenção do cuidado deveria instigar gestores e profissionais de saúde a rever seus trabalhos e repensar o atendimento que está sendo realizado.

\section{Conclusão}

Este estudo buscou analisar as publicaçóes brasileiras relativas à gestáo do cuidado na Estratégia Saúde da Família, considerando que refletir sobre essa temática implica reconhecer novos modos de ver as práticas de cuidado em saúde. Isso porque os profissionais têm o compromisso de, continuamente, gerar mudanças e transformaçóes em suas práxis, com a finalidade de melhorar e qualificar a assistência e a satisfação do usuário.

A análise dos textos possibilitou identificar que o modelo de gestão da ESF requer que os profissionais, gestores e usuários identifiquem os problemas e construam soluçôes juntos. Além disso, os trabalhadores devem estar capacitados para dar suporte à comunidade, contribuindo para a promoção da saúde e do cuidado. $\mathrm{O}$ fortalecimento da equipe permitirá a identificação precoce dos problemas, o acolhimento e a criação do vínculo, elementos fundamentais da integralidade da atenção em saúde.

Desse modo, a ESF se constitui em um espaço em que profissionais e usuários podem discutir ações e intervençôes em prol da saúde da população. Para tanto, a construção do vínculo e a satisfação de ambos são fundamentais para a obtenção do sucesso no processo de cuidar, se constituindo na dimensão profissional da gestão do cuidado. Contudo, a execuçáo da gestão do cuidado na ESF ainda permanece como um dos desafios para os trabalhadores e gestores. Evidencia-se, nos artigos pesquisados, que há fragilidades nas organizaçôes dos serviços de saúde, o que gera insatisfação dos usuários. Para tanto, é necessário que os gestores criem processos de discussão e reflexôes sobre a gestão do cuidado, em conjunto com os profissionais que atuam na ESF e os usuários, que também fazem parte da organização.

Por fim, os estudos apontam que a gestão do cuidado deve valorizar o uso das tecnologias leves como o vínculo e acolhimento entre profissionais e usuários. Nesse contexto, esta investigação possibilitou a realização de reflexôes acerca das investigaçóes no âmbito assistencial, ensino e de pesquisa no que tange à gestão do cuidado, na perspectiva de ampliação do conhecimento nesses campos.

\section{Referências}

1. Beck CL, Minuzi DO. Acolhimento como proposta de reorganização da assistência à saúde: uma análise bibliográfica. Saúde, Santa Maria. 2008;34(1-2):37-43.

2. Neves OJ, Meneghim MC, Pereira AC. Estratégia da Saúde da Família em Manaus: uma avaliaçáo dos aspectos administrativos e operacionais. Odonto. 2012;20(39):99-109.

3. Luzardo AR, Pereira MF, Pereira J. Modelo de gestáo do cuidado em Atenção Primária: reflexôes sobre determinantes sociais da saúde do idoso. In: Pereira MF, Costa AM, Moritz GO, Bunn DA. Contribuiçóes para a gestão do SUS. Florianópolis: Fundação Boiteux; 2013. 222p. (Gestão da Saúde Pública; v. 10).

4. Merhy EE. Em busca do tempo perdido: a micropolítica do trabalho vivo em saúde. In: Merhy EE, Onocko R, (orgs.). Agir em saúde: um desafio para o público. São Paulo: Hucitec; 1997. p. 71-112.

5. Cecilio LCO. A morte de Ivan Ilitch, por Leo Tolstoy: elementos para se pensar a múltiplas dimensóes da gestão do cuidado. Interface - Comunic Saúde Educ. 2009; 13(Supl.1):545-55.

6. Polit DF, Hungler BP. Fundamentos de pesquisa em enfermagem. $7^{\mathrm{a}}$ ed. Porto Alegre: Artes Médicas; 2011.

7. Bardin L. Análise de conteúdo. Lisboa: Ediçôes 70; 2010.

8. Correia VR, Barros S, Colvero LA. Saúde mental na atenção básica: prática da equipe de saúde da família. Rev. esc. enferm. 2011;45(6):1501-6.

9. Waidman MAP, Costa B, Paiano M. Percepções e atuação do Agente Comunitário de Saúde em saúde mental. Rev Esc Enferm. 2012: 46(5):1170-77.

10. Seabra DC, Carvalho ACD, Foster AC. O Agente Comunitário de Saúde na visão da equipe mínima de Saúde. Rev. APS. 2008;11(3):226-43.

11. Brand CI, Antunes RM, Fontana RT. Satisfaçôes e insatisfaçóes no trabalho do agente comunitário de saúde. Cogitare enferm. 2010;15(1):40-7.

12. Munari DB, Melo TS, Oliveira MB, Barbosa CC, Queiroz ACCM, Araújo BFM. Capacitação de agentes comunitários de saúde para o cuidado em saúde mental na atenção básica: potencializando pessoas para cuidar de pessoas. Rev Tempus Actas Saúde Colet. 2010;4(1):115-23. 
13. Martins JS, Garcia JF, Passos ABB. Estratégia saúde da família: população participativa, saúde ativa. Rev Enferm Integrada. 2008;1(1):sp.

14. Brasil. Ministério da Saúde. Linha de cuidado para a atenção integral à saúde de crianças, adolescentes e suas famílias em situaçáo de violência. Orientaçóes para gestores e profissionais de saúde. Brasília; 2010.

15. Gonçalves RJ, Soares RA, Troll T, Cyrino EG. Ser médico no PSF: formação acadêmica, perspectivas e trabalho cotidiano. Rev bras educ med. 2009;33(3):382-92.

16. Marqui ABT, Jahn AC, Resta DG, Colomé ICS, Rosa N, Zanon T. Caracterização das equipes da Saúde da Família e de seu processo de trabalho. Rev Esc Enferm. 2010;44(4):956-61.

17. Roecker S, Lazzarotto EM, Dutra JU. Dificuldades encontradas por enfermeiros no gerenciamento de equipes de saúde da família no âmbito da $10^{\circ}$ regional de saúde. In: $4^{\circ}$ Seminário Nacional Estado e Políticas Sociais; 2009 set 16-19; Cascavel: Unioeste; 2009.
18. Bôas LMFMV, Araújo MBS, Timóteo RPS. A prática gerencial do enfermeiro no PSF na perspectiva da sua ação pedagógica educativa: uma breve reflexão. Ciênc saúde coletiva. 2008;13(4):1355-60.

19. Medeiros FGC, Araújo-Souza GC, Albuquerque-Barbosa AA, Clara-Costa IC. Acolhimento em uma Unidade Básica de Saúde: a satisfação do usuário em foco. Rev salud pública. 2010;12(3):402-13.

20. Nery AA, Carvalho CGR, Santos FPA, Nascimento MS, Rodrigues VP. Saúde da família: visão dos usuários. Rev enferm UERJ. 2011;19(3):397-402.

21. Santos SMS, Oliveira VAC, Oliveira RAC, Guimarães EAA. Estratégia saúde da família: qualidade da assistência sob a perspectiva da satisfação do usuário. Reme-Revista Mineira de Enfermagem. 2010;14(4):499-508.

22. Santos HT. Estratégia Saúde da Família: satisfação de usuários. [Dissertação de (Mestrado]. Ribeirão Preto: Universidade de São Paulo; 2011.

\section{Como citar este artigo:}

Leite MT, Nardino J, Hildebrandt LM, Santos AM, Martins RV. Gestão do cuidado na estratégia saúde da família: revisão narrativa. Rev. Aten. Saúde. 2016;14(48):106-115. 